\title{
Correction to: Antileishmanial Activity of Lignans, Neolignans, and Other Plant Phenols
}

Jiř́i Pospíšil, Daniela Konrádová, and Miroslav Strnad

\section{Correction to:}

Chapter "Antileishmanial Activity of Lignans, Neolignans, and Other Plant Phenols" in: A. D. Kinghorn, H. Falk, S. Gibbons, Y. Asakawa, J.-K. Liu, V. M. Dirsch (eds.), Progress in the Chemistry of Organic Natural Products Vol. 115, https://doi.org/10.1007/978-3-030-64853-4_3

The original version of the book was inadvertently published with incorrect figures (Fig. 3 and Fig. 14) in Chapter 3. The erratum chapter has been updated with the changes and the correct presentation is given here: 


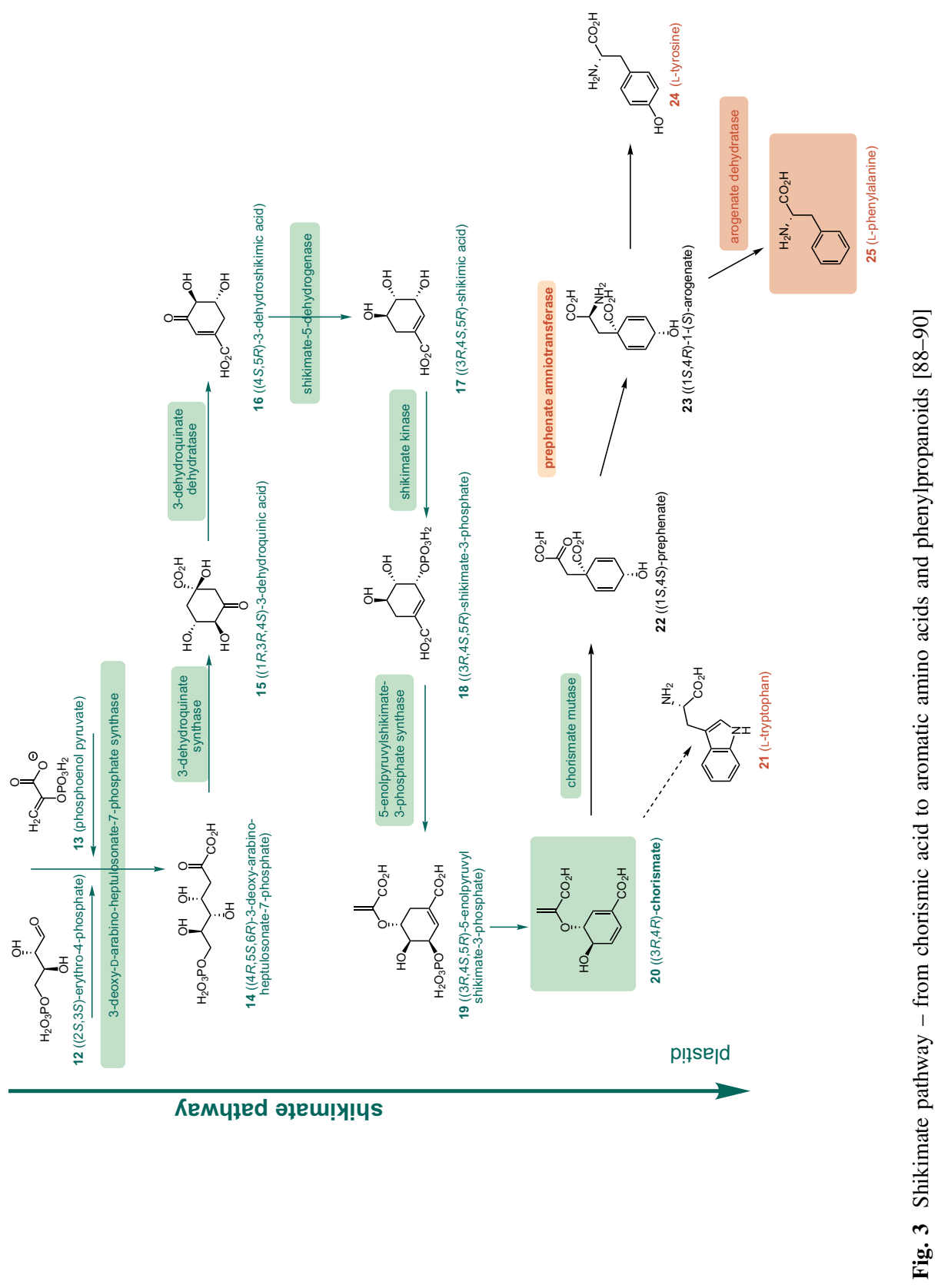




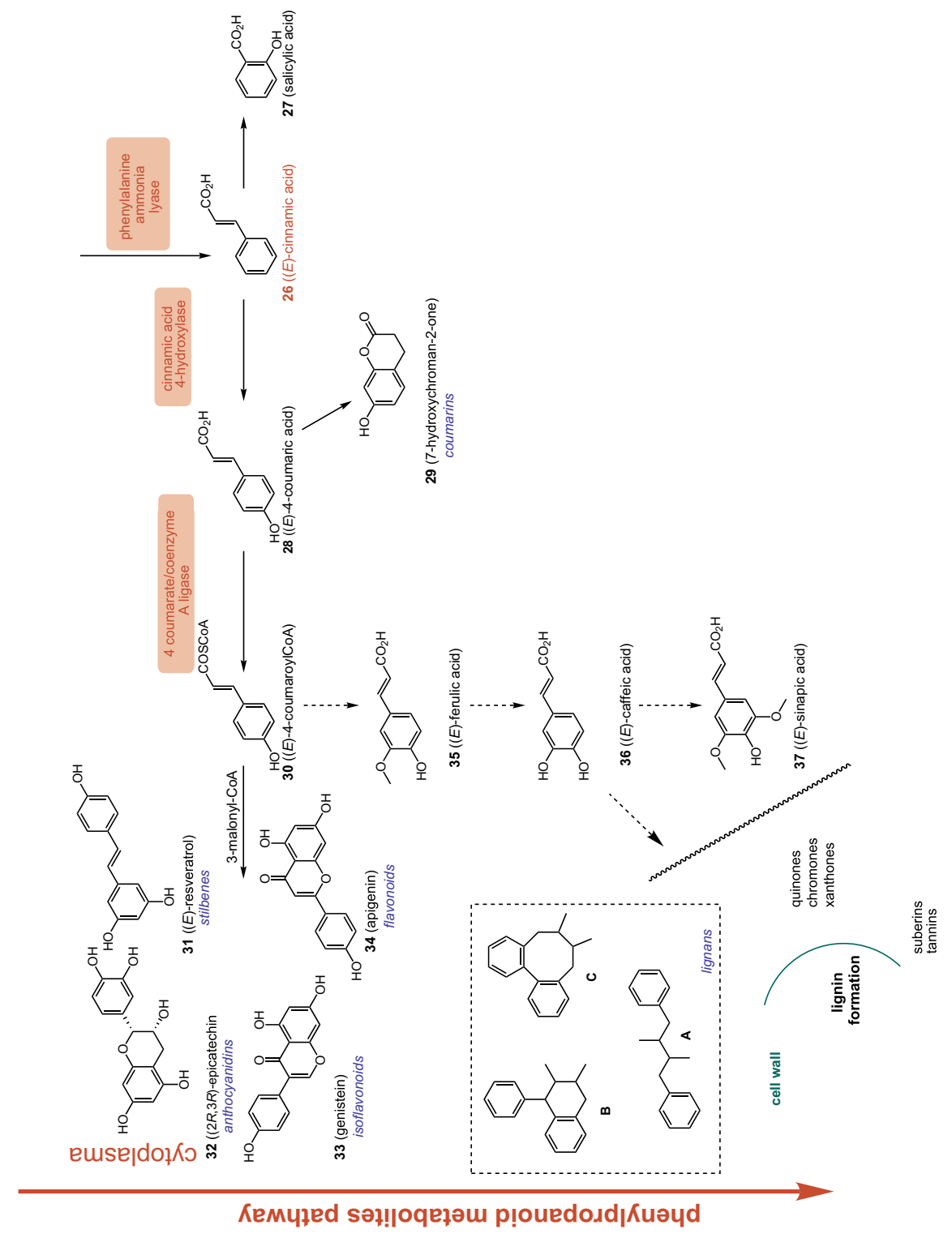


<smiles>Oc1ccc(C=Cc2cc(O)cc(O)c2)cc1</smiles>

31 (resveratrol)

proliferation/apoptosis modulation

angiogenesis modulation

metastasis inhibition

redox status modulation

adipogenesis suppresion

osteogenesis stimulation

mitochondrial activity modulation

DNA damage modulation

xenobiotic metabolism modulation

glutamate metabolism modulation

autophagy modulation
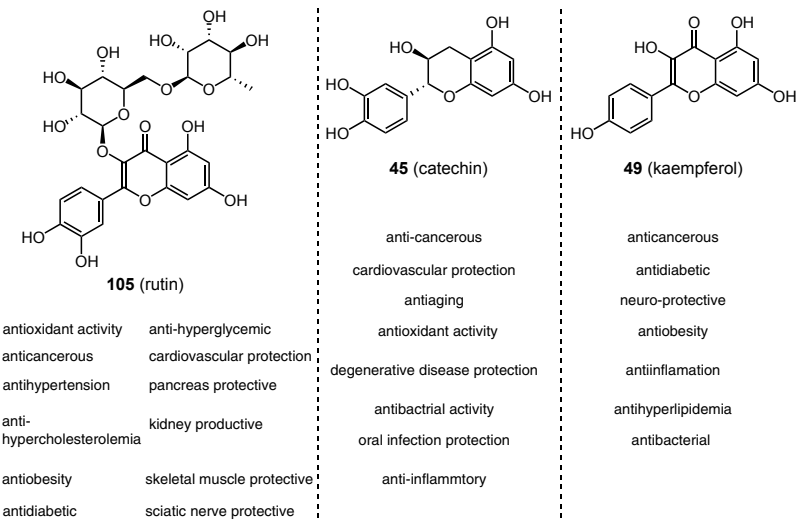

Fig. 14 Structurally important phenolic compounds - resveratrol, rutin, catechin, and kaempferol — and their biological activities 